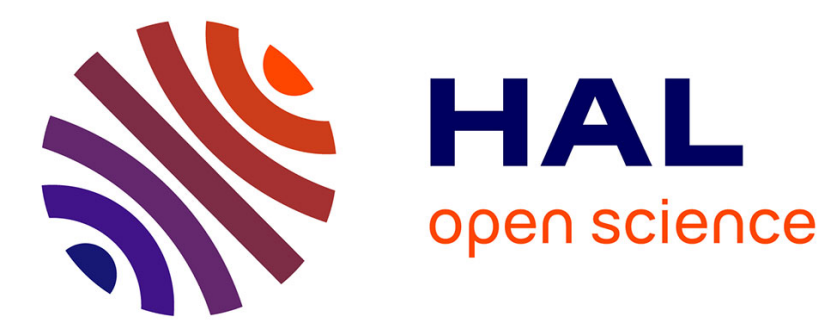

\title{
Artificial light may change flight patterns of bats near bridges along urban waterways
}

Kévin Barré, Kamiel Spoelstra, Yves Bas, Samuel Challéat, Ros Kiri Ing, Clémentine Azam, Georges Zissis, Dany Lapostolle, Christian Kerbiriou, Isabelle Le Viol

\section{To cite this version:}

Kévin Barré, Kamiel Spoelstra, Yves Bas, Samuel Challéat, Ros Kiri Ing, et al.. Artificial light may change flight patterns of bats near bridges along urban waterways. Animal Conservation, 2021, 24 (2), pp.259-267. 10.1111/acv.12635 . hal-02914600

\section{HAL Id: hal-02914600 https://hal.science/hal-02914600}

Submitted on 12 Aug 2020

HAL is a multi-disciplinary open access archive for the deposit and dissemination of scientific research documents, whether they are published or not. The documents may come from teaching and research institutions in France or abroad, or from public or private research centers.
L'archive ouverte pluridisciplinaire HAL, est destinée au dépôt et à la diffusion de documents scientifiques de niveau recherche, publiés ou non, émanant des établissements d'enseignement et de recherche français ou étrangers, des laboratoires publics ou privés. 


\section{Artificial light may change flight patterns of bats near bridges}

\section{2 along urban waterways}

Kévin Barré ${ }^{1,2}$, Kamiel Spoelstra ${ }^{3}$, Yves Bas ${ }^{1,4}$, Samuel Challéat ${ }^{5}$, Ros Kiri Ing ${ }^{6}$, Clémentine

Azam $^{7}$, Georges Zissis ${ }^{8}$, Dany Lapostolle ${ }^{9}$, Christian Kerbiriou ${ }^{1,2 *}$, Isabelle Le Viol ${ }^{1,2 *}$

${ }^{1}$ Centre d'Ecologie et des Sciences de la Conservation (CESCO), Muséum national d'Histoire naturelle, Centre National de la Recherche Scientifique, Sorbonne Université, CP 135, 57 rue

Cuvier, 75005 Paris, France

${ }^{2}$ Centre d'Ecologie et des Sciences de la Conservation (CESCO), Muséum national d'Histoire naturelle, Station de Biologie Marine, 1 place de la Croix, 29900 Concarneau, France

${ }^{3}$ Department of Animal Ecology, Netherlands Institute of Ecology (NIOO-KNAW), PO Box 50, $6700 \mathrm{AB}$ Wageningen, The Netherlands

Franche-Comté, 32 rue Mégevand, 25030 Besançon, France 
Corresponding author:

27

Kévin Barré

kevin.barre@edu.mnhn.fr

$29+33298509928$

30

31 Running head: Waterway lighting changes bat flight patterns

32 


\section{Abstract}

Artificial light at night (ALAN) is considered as a major threat to biodiversity, especially to nocturnal species, as it reduces availability, quality and functionality of habitats. However, its effects on the way species use landscape elements such as rivers are still largely understudied, especially the effect of crossing infrastructure lighting on bridges. These elements are nevertheless key commuting and foraging habitats in heavily urbanised landscapes for several taxa such as bats that are particularly affected by ALAN. We studied the effects of the illumination of facades and undersides of bridges on the relative abundance of pipistrelle bats, on their 3D distribution and their behavioural response (i.e. flight speed) close to bridges. We set-up an innovative approach based on a microphone-array to reconstruct positions and flight trajectories in 3D. We studied the effect of lighting on bats in the close proximity of six similar bridges, mostly differentiated by the presence or absence of lighting (3 lit and 3 unlit). All bridges cross the same waterway, within a uniformly and highly urbanized agglomeration (Toulouse, France). We found that bat activity was 1.7 times lower in lit sites. Bats tended to keep a larger distance, and to fly faster close to illuminated bridges. These results suggest that bridge lighting strongly reduces habitat availability and likely connectivity for bats. In that case, results call for switching off the illumination of such bridges crossing riverine ecosystems to preserve their functionality as habitats and corridors for bats.

\section{Key words: acoustic localisation, artificial light, Chiroptera, ecological corridor, flight} behaviour, light pollution, microphone array, river 


\section{Introduction}

Among the most prevalent sources of change in biodiversity state, Artificial Light At Night (ALAN) is increasingly recognized as a new threat (Koen et al., 2018). ALAN impacts a wide range of taxa, from individual physiological response to ecosystem functioning, interactions between species and regulatory processes (Bennie et al., 2018; Hölker et al., 2010; Knop et al., 2017; Salinas-Ramos et al., 2020) at many spatiotemporal scales (Altermatt and Ebert, 2016; Gaston et al., 2017).

ALAN particularly affects nocturnal species such as bats. ALAN affects the availability, quality and functionality of habitats for bats, by changing environmental conditions in which bats interact with other taxa at different spatial scales: their prey, their predators, and likely their competitors (Cravens et al., 2017; Jones and Rydell, 1994; Minnaar et al., 2015; Russo et al., 2019). First of all, it affects the abundance and the distribution of their prey, i) by massively attracting insects around light sources at the streetlight scale ii) and by inducing a suspected vacuum cleaner effect in the surrounding dark areas (Eisenbeis, 2006; Perkin et al., 2014). ALAN also induces mortality and changes in community composition of insects (Davies et al., 2012) in such a way that ALAN is suggested to be a major driver of large scale decline in insects' populations (Fox, 2013; Frank, 1988) and consequently in bat prey availability. By illuminating the scene, ALAN is also suggested to increase predation risk of bats by owls and other raptors (Jones and Rydell, 1994), and in turn bats increase their flight speed (Polak et al., 2011). Bat species respond differently to these changes in interactions with other taxa according to their flight type. Slow-flying species adapted to forage on insects in cluttered vegetation, such as Myotis spp., Plecotus spp. and Rhinolophus spp. avoid lit areas (Clémentine Azam et al., 2015; Zeale et al., 2018), while fast-flying species adapted to hunt insects in open space, such as Pipistrellus spp., may appear to benefit locally from the aggregated prey resources around streetlight (Clémentine Azam et al., 2015; Rydell, 1992), 
although at a wider scale, ALAN negatively impacts their relative abundance (Azam et al., 2016; Pauwels et al., 2019).

By reducing habitat availability and quality, ALAN was also suggested to decrease the functional connectivity of landscapes for bats (Laforge et al., 2019) and can have dramatic impacts on their relative abundance at a larger scale (Azam et al., 2016; Pauwels et al., 2019). Linear landscape elements such as hedgerows and rivers play an essential role for bats commuting between roosts and foraging patches (Akasaka et al., 2012; Lacoeuilhe et al., 2016; Pinaud et al., 2018; Smith and Racey, 2008). Such landscape elements also provide dark corridors in dimly lighted situations (full moon or distant lighting) (Ancillotto et al., 2019; Zeale et al., 2018) and are specifically important in illuminated urban landscape. ALAN is nevertheless worldwide increasing, in particular close to protected areas and biodiversity hotspots (Guetté et al., 2018), for security, use or aesthetic reasons. This lighting hinders bats when crossing gaps in wooded linear corridors (Hale et al., 2015) and reduces the number of bat commuting along hedgerows (Zeale et al., 2018). Among linear landscape elements, riverine ecosystems are key habitats for bats. Their riparian vegetation and water surface are important foraging areas for many bat species and are recognized as determinants to explain bat abundance across the landscape (Carrasco-Rueda and Loiselle, 2019; Downs and Racey, 2006; Grindal et al., 1999; Lloyd et al., 2006; Lookingbill et al., 2010; Sirami et al., 2013). In highly urbanized areas rivers or waterways and their associated riparian vegetation are often the only corridors still relatively dark, and are thus of high importance for bat moving through such illuminated landscapes (Laforge et al., 2019; Lintott et al., 2015; Todd and Williamson, 2019). However, ecological consequences of the illumination of rivers remain largely understudied (Jechow and Hölker, 2019). Only one study to our knowledge investigated the effect of ALAN on commuting bats by recording Daubenton's bats (Myotis daubentonii) passing through culverts. In this study the bat activity was found to be 
unaffected by the presence of light (Spoelstra et al., 2018). However, another study showed that most bat species, including Myotis species, significantly reduced their number of drinking and activity above water in presence of artificial light (Russo et al., 2019, 2018, 2017).

However, studying bats using such activity metrics from acoustic recordings does not inform on all behavioural changes (e.g. flight speed, spatial position). The development of microphone arrays allows high-resolution localization of bats using their echolocation calls, and hence tracking the animal's movement (Koblitz, 2018). Precise tracking of bats appears as an innovative and a promising method for assessing poorly studied impacts of light on flight behaviour, such as flight speed and changes in flight path.

Here, we aim to assess how the illumination of bridges over waterways affects bat activity and their flight behaviour along riverine ecosystems. We studied six bridges above a waterway in a highly urbanized area to assess the impact of facade and underbridge lighting on bats. In addition to activity measurements, we used a microphone-array to record bat positions to construct 3D bat flight trajectories in order to calculate flight speeds. When approaching a lighted structure across a riverine ecosystem, we hypothesize that bats have to deal with a trade-off that includes the benefits of foraging and commuting along this corridor, and the drawback of increased predation risk by exposure to light. In the case of bats limit the risk of exposure to light (Jones and Rydell, 1994; Russo et al., 2018), we predict a decrease in passing bats through light cone and in approaches of individuals to lit bridges. Light sources at riverine ecosystems could therefore form a barrier for moving along it (Hale et al., 2015). In case bats do fly through light cone, they possibly try to minimize the risk of predation by increasing their flight speed (Polak et al., 2011). 


\section{Material and methods}

129

130

131

132

Study sites

We carried out the study on three lit and three unlit bridges. These six bridges were across two branches of a waterway with a comparable width (around $30 \mathrm{~m}$ ) and stagnant water (i.e. low current), at the centre of a highly urbanized area (in the city of Toulouse, France, N 43.60 E 1.43; Fig. S1). Among bridges studied, four were road bridges (two lit and two unlit) and two were footbridges (one lit and one unlit). Bridges were chosen such that these were comparable in shape (height and width; Table $1 \&$ Fig. S1) and surrounding vegetation (Fig. S1). The lit bridges have been illuminated for many years, with all-year lighting of the facade and underside from the sunset until 1:00 a.m., while unlit bridges had no illumination at all (Fig. S1). Since all the sites were located in very dense urban areas, we assumed that background light from the surrounding city was comparable for all sites. Lit sites were on average exposed to twice as much light than unlit sites: respectively $7.4 \pm 1.4$ lux for lit sites and 3.6 \pm 1.6 lux for unlit sites (Table 1; see Supporting information S1 for details about light measurements).

\section{Sampling design and 3D acoustic tracking}

We studied the effect of bridge-illumination on bat activity, bat-bridge distance and associated flight speed, through comparisons between lit and unlit sites. We therefore recorded and localized bats in three dimensions on the three first hours starting from sunset during 6 consecutive nights between the $19^{\text {th }}$ and $25^{\text {th }}$ of June 2018 (Koblitz, 2018). Weather conditions were highly stable and optimal throughout this sampling period (average temperature: $24.5 \pm 1.5{ }^{\circ} \mathrm{C}$, average wind:3.3 $\pm 1.1 \mathrm{~m} / \mathrm{s}$, no rain and no cloud; Table $\mathrm{S} 1$ ). Between consecutive nights, we alternated each night sampling near lit and unlit bridges. 
To sample bats, we used an acoustic localisation system (hereafter named microphone array) designed at the Institut Langevin by Ros Kiri Ing (see Supporting Information S2 for more details about the system) (Ing et al., 2016), with a detection radius of about $20 \mathrm{~m}$. Arrays were placed as close as possible to the bridge where the nature of the ground allowed to install the microphone array (i.e. 16.2, 11.7 and $10.5 \mathrm{~m}$ from lit bridges, and 10.5, 8.5 and $6 \mathrm{~m}$ from unlit bridges). Consequently, the microphone array was placed at the same distance from bridges for only one pair of lit/unlit bridges (i.e. $10.5 \mathrm{~m}$ ), We accounted for these differences in array-bridge distances in statistical analysis (see statistical analysis section).

Each position of bats was reconstructed in 3D using time differences of arrival (TDOA) (Koblitz, 2018) of one echolocation call following the Ing et al. (2016) approach. While relatively seldom used for bat studies, this innovative approach of acoustic localisation has already proven its worth (Götze et al., 2020; Ing et al., 2016; Koblitz, 2018; Polak et al., 2011). We chose to discard positions with a cumulated imprecision greater than one meter on the three dimensions (i.e. the sum of the imprecision on each dimension). Spatial location of bats around the microphone array then allowed the computation of the distance of each emitted bat call to the bridge (see Supporting information S3 for more details on calculation). We then computed flight speed (Equation 1) as follows:

$$
V_{i}=\frac{\sqrt{\left(x_{i}-x_{j}\right)^{2}+\left(y_{i}-y_{j}\right)^{2}+\left(z_{i}-z_{j}\right)^{2}}}{t_{i}-t_{j}}
$$

where $x, y$ and $z$ represent distances to the microphone array for each of the three-dimension axis, and $t$ is the time of call arrival to the microphone array of a given position $i$ and its previous position $j$ (see Supporting information S3 for more details).

Although the number of sampled sites was low due to technical constraints, the method using microphone arrays allowed to measure a high number of positions with high precisions. 
Assigning species to $3 D$ positions and quantification of the number of passing bats

The microphone arrays continuously recorded the echolocation calls of passing bats which were stored in sound files (Ing et al., 2016). These files were divided in five-second files, a sufficient interval for the average duration of a bat pass (Kerbiriou et al., 2019). Hereafter, a bat pass was thus defined as a single or several echolocation calls within a five-second interval. Only $0.6 \%$ of 5 -second recordings contained more than one individual. Each fivesecond file was classified to the closest taxonomic level using Tadarida software (Bas et al., 2017). We also visually inspected sound files for feeding buzzes during each bat pass, i.e. rapid sequences of short linear calls before the prey capture.

Because the identification at the species level can be problematic, we limited identification level to the species group. We limited further analysis to the Pipistrellus group, which includes Pipistrellus kuhlii, Pipistrellus pipistrellus, Pipistrellus pygmaeus, and Pipistrellus nathusii. The other bat species groups were absent or showed only a couple of passes preventing any analyses. We subsequently linked the 3D bat position calculated for each call to the species group assigned to it by Tadarida. See Supporting information S4 and R script for more details about automated identification and assigning species to 3D positions.

\section{Statistical analysis}

We first compared bat activity between lit and unlit sites, using the number of bat passes instead of the number of bat positions, because increasing flight speed reduces the number and the precision of positions (Table 1).

To test for potential difference of bat-bridge distances between unlit and lit bridge sites, we built a Linear Mixed Model (LMM, R package TMB) using the bat-bridge distance as the response variable following a Gaussian error distribution (Fig. 1), and the lighting treatment (i.e. lit or unlit bridge), the array-bridge distance, the square of the array-bridge distance, and 
the interaction between both array-bridge distance variables and the lighting treatment as fixed explanatory variables. We used the array-bridge distance as a covariate because lit sites were sampled on average slightly closer to bridges than unlit sites due to field constraints (Table 1; Fig. S2). We included the site as a random effect in models to account for the spatial-temporal structure of the sampling design of recordings (i.e. several recordings per site, one site sampled per night)

We then tested whether flight speed changed according to the distance to light. We performed LMM using the flight speed as the response variable associated with a Gaussian error distribution (Fig. S3), the lighting treatment (i.e. lit or unlit bridge), the array-bridge distance, the bat-bridge distance (i.e. for every position for which a flight speed was computed), the square of the bat-bridge distance as fixed explanatory variables. The square of the bat-bridge distance was included as explanatory variable after visual inspection of their non-linear nature in a Generalized Additive Mixed Model using the gamm function (R package $m g c v$ ). As flight speed is expected to vary with lighting (Polak et al., 2011), we also included two interaction terms between the bat-bridge distance, respectively the square of the bat-bridge distance, and the lighting treatment (i.e. lit or unlit bridge). Since flight speed was computed for positions which were part of bat individual trajectories composed of several positions (see Supporting Information S2 for trajectory reconstruction), we accounted for this individual nesting by adding a random effect on the trajectory identity. We also included the site as a second random effect. Given that imprecisions of positions were positively correlated with their distance to the microphone array and the flight speed (Pearson correlation tests: $t=18.5$, $\mathrm{df}=2185, \mathrm{p}$-value $<0.001$ and $\mathrm{t}=17.2, \mathrm{df}=1349, \mathrm{p}$-value $<0.001$, respectively), we gave to the response variable different weights according to their associated precision by adding a weight term in LMMs (i.e. one per imprecision squared; Penone et al., 2013). We then selected for models with the lowest AIC values, and with VIF values lower than 2 to avoid collinearity 
issues (Zuur et al., 2010). We re-ran this model for road and footbridges separately to assess the potential dependence of results to the type of bridge. Finally, because the microphone array was placed at the same distance from bridges for only one pair of lit/unlit bridges (i.e. $10.5 \mathrm{~m}$ ), we focused a last model only on positions that were located between 10.4 to $13.5 \mathrm{~m}$

230 from bridges, i.e. that corresponded to the overlap of the $95 \%$ confidence interval of bat 231 distances from lit bridges and the 95\% confidence interval of bat distances from unlit bridges (see right panel of the Fig. 1). This model was identical to the previous ones but without the bat and array-bridge distance variables as it only focuses on a restricted range of distances, where there is maximum confidence in the results by limiting the array-bridge distance bias. Finally, it was not technically possible to measure light intensity with sufficient precision for each bat position due to the presence of the waterway. We therefore used the bat-bridge distance variable assuming it could be a good proxy due to the relationship between the light intensity and the distance to light. All analyses were performed using a significance threshold of 5\% in the R statistical software (R Core Team, 2018). 


\section{Results}

242 We recorded 644 bat passes of Pipistrellus spp. at unlit sites (respectively 179, 212, 253 bat

243 passes per site) while only 386 at lit sites (respectively 106, 136, 144 bat passes per site; Table

244 1), i.e.1.7 times less bat passes at lit compared to unlit sites. We also recorded four passes of

245 Myotis spp. and 12 passes of Nyctalus spp. The Pipistrellus group was composed of $73.1 \%$

Pipistrellus kuhlii/nathusii, 26.4\% Pipistrellus pipistrellus and 0.5\% Pipistrellus pygmaeus.

Pipistrellus spp. emitted in total 21 feeding buzzes (i.e. during $2 \%$ of all passes), all at unlit

sites (Table 1). We also recorded more 3D bat position at unlit sites (i.e. 2036) than at lit sites

(i.e. 151) (Table 1).

Bat positions were located significantly closer to unlit bridges than lit bridges (Table 2). At

the $10.5 \mathrm{~m}$ array-bridge distance at which unlit and lit sites were both sampled, bats were in

Table 1. Summary per site of study sites characteristics, sampling design and bat survey results.

\begin{tabular}{|c|c|c|c|c|c|c|c|c|c|c|}
\hline Sites & Date & $\begin{array}{l}\text { Lighting } \\
\text { treatment }\end{array}$ & $\begin{array}{c}\text { Bridge type } \\
\text { (height - } \\
\text { width in } \\
\text { meters) }\end{array}$ & $\begin{array}{l}\text { Array- } \\
\text { bridge } \\
\text { distance } \\
\text { (m) }\end{array}$ & $\begin{array}{l}\text { Light } \\
\text { intensity } \\
\pm \mathrm{SD} \\
\text { (Lux) }\end{array}$ & $\begin{array}{l}\text { Number } \\
\text { of 3D } \\
\text { positions }\end{array}$ & $\begin{array}{l}\text { Number } \\
\text { of } 5 \\
\text { seconds } \\
\text { bat passes } \\
\text { (buzzes) }\end{array}$ & $\begin{array}{c}\text { Average } \\
\text { bat-bridge } \\
\text { distance } \pm \\
\text { SD (m) }\end{array}$ & $\begin{array}{c}\text { Average } \\
\text { flight } \\
\text { speed } \pm \\
\text { SD } \\
(\mathrm{m} / \mathrm{s})\end{array}$ & $\begin{array}{c}\text { Average } \\
\text { imprecision } \\
\text { on } \\
\text { positions } \pm \\
\text { SD }(\mathrm{cm})\end{array}$ \\
\hline 1 & $19 / 06 / 2018$ & Lit & $\begin{array}{l}\text { Road bridge } \\
(7.2-29.7)\end{array}$ & 16.2 & $9.1 \pm 8.8$ & 107 & $144(0)$ & $15.7 \pm 1.8$ & $8.2 \pm 1.3$ & $54.1 \pm 27.0$ \\
\hline 2 & $21 / 06 / 2018$ & Lit & $\begin{array}{l}\text { Road bridge } \\
(5.5-17.8)\end{array}$ & 11.7 & $7.9 \pm 8.2$ & 26 & $106(0)$ & $10.7 \pm 1.8$ & $6.8 \pm 2.0$ & $48.2 \pm 22.9$ \\
\hline 3 & $24 / 06 / 2018$ & Lit & $\begin{array}{l}\text { Footbridge } \\
(6.0-2.5)\end{array}$ & 10.5 & $5.3 \pm 3.6$ & 18 & $136(0)$ & $12.6 \pm 1.5$ & $8.5 \pm 1.3$ & $54.5 \pm 22.0$ \\
\hline 4 & $20 / 06 / 2018$ & Unlit & $\begin{array}{l}\text { Road bridge } \\
(5.7-22.8)\end{array}$ & 8.5 & $4.7 \pm 8.8$ & 779 & $179(3)$ & $7.1 \pm 2.9$ & $6.5 \pm 2.3$ & $16.0 \pm 13.8$ \\
\hline 5 & $22 / 06 / 2018$ & Unlit & $\begin{array}{l}\text { Road bridge } \\
(6.5-29.3)\end{array}$ & 10.5 & $4.9 \pm 4.1$ & 263 & 253 (10) & $10.0 \pm 2.1$ & $5.7 \pm 2.0$ & $59.2 \pm 27.7$ \\
\hline 6 & $25 / 06 / 2018$ & Unlit & $\begin{array}{l}\text { Footbridge } \\
(6.2-2.6)\end{array}$ & 6.0 & $1.2 \pm 0.3$ & 994 & $212(8)$ & $5.7 \pm 3.6$ & $6.3 \pm 2.4$ & $12.3 \pm 14.3$ \\
\hline $1+2+3$ & I & Lil & I & 14.7 & $7.4 \pm 1.4$ & 151 & 386 & $14.5 \pm 2.7$ & $8.1 \pm 1.5$ & $53.1 \pm 25.8$ \\
\hline $4+5+6$ & 1 & Unlit & 1 & 7.5 & $3.6 \pm 1.6$ & 2036 & 644 & $6.8 \pm 3.5$ & $6.3 \pm 2.3$ & $19.8 \pm 22.5$ \\
\hline
\end{tabular}


with respective null models.

\begin{tabular}{|c|c|c|c|c|c|}
\hline Response variable & Explanatory variables & Estimate $\pm \mathrm{SE}$ & $\mathrm{z}$ value & p-value & $\Delta \mathrm{AIC}$ \\
\hline \multirow{6}{*}{ Bat-bridge distance } & Intercept & $27.230 \pm 4.527$ & 6.015 & $<0.001$ & \multirow{6}{*}{-60} \\
\hline & Unlit $v$ s.lit bridge & $-26.145 \pm 4.529$ & -5.773 & $<0.001$ & \\
\hline & Array-bridge distance & $-2.727 \pm 0.673$ & -4.055 & $<0.001$ & \\
\hline & Array-bridge distance ${ }^{\wedge}$ & $0.129 \pm 0.024$ & 5.315 & $<0.001$ & \\
\hline & Unlit $v s$.lit bridge : Array-bridge distance & $3.093 \pm 0.673$ & 4.593 & $<0.001$ & \\
\hline & Unlit $v s$. lit bridge : Array-bridge distance ${ }^{\wedge} 2$ & $-0.072 \pm 0.024$ & -2.964 & 0.003 & \\
\hline \multirow[t]{7}{*}{ Flight speed } & Intercept & $-0.961 \pm 2.537$ & -0.379 & 0.705 & \multirow{7}{*}{-2565} \\
\hline & Unlit $v s$. lit bridge & $8.832 \pm 2.221$ & 3.977 & $<0.001$ & \\
\hline & Bat-bridge distance & $2.043 \pm 0.294$ & 6.954 & $<0.001$ & \\
\hline & Bat-bridge distance ${ }^{\wedge} 2$ & $-0.082 \pm 0.011$ & -7.573 & $<0.001$ & \\
\hline & Array-bridge distance & $-0.185 \pm 0.096$ & -1.929 & 0.054 & \\
\hline & Unlit vs.lit bridge : Distance to the bridge & $-2.083 \pm 0.294$ & -7.088 & $<0.001$ & \\
\hline & Unlit $v s$. lit bridge : Distance to the bridge ${ }^{\wedge}$ & $0.089 \pm 0.011$ & 8.250 & $<0.001$ & \\
\hline \multirow{3}{*}{$\begin{array}{l}\text { Flight speed in the } \\
\text { overlap between } 95 \% \\
\text { confidence intervals } \\
\text { of positions of lit and } \\
\text { unlit sites }\end{array}$} & Intercept & $8.708 \pm 0.625$ & 13.930 & $<0.001$ & \multirow[b]{3}{*}{-5.5} \\
\hline & Unlit $v s$. lit bridge & $-2.175 \pm 0.677$ & -3.214 & 0.001 & \\
\hline & & & & & \\
\hline
\end{tabular}

263 Bats were overall flying significantly faster in nearby lit bridges compared to unlit bridges.

264 Flight speeds were for example $8.7 \mathrm{~m} / \mathrm{s}$ for lit sites and $6.5 \mathrm{~m} / \mathrm{s}$ for unlit sites on average

265 within the range of distances between 10.4 and $13.5 \mathrm{~m}$ from bridges (i.e. the range including an overlap of $95 \%$ between bat positions from lit and bat positions from unlit bridges; Table

267 2; Fig. 2). The relationship between the flight speed and the bat-bridge distance was thus

268 found to strongly differ between unlit and lit bridges (Table 2; Fig.2): Flight speed was found 269 to significantly decrease when bats approached unlit bridges, while we found significant

270 increasing of speeds when bats approached lit bridges (Table 2; Fig. 2). The array-bridge

271 distance was not found to significantly influence results about flight speeds (Table 2). Finally,

272 bats responded the same to footbridges and road bridges (Figs. S4 \& S5), the results were thus

273 independent of differences in usage, structure and lighting way. 




Figure 1. Predicted average bat-bridge distances in unlit and lit sites according to the array-bridge distance of

277 sampling. This interaction comes from the linear mixed model presented in Table 2. Vertical bars at the bottom show the three array-bridge distances sampled in unlit sites (black), and the three sampled in lit sites (grey). The representation on the right panel shows a theoretical top-view of bat localisations (filled circles) and average bat localisation (blank circles) according to the lighting type of bridges, and shown for the array-bridge distance of

$28110.5 \mathrm{~m}$ shared by two sampling sites. The light grey rectangles show the overlap of the $95 \%$ confidence interval of bat distances from lit bridges and the $95 \%$ confidence interval of bat distances from unlit bridges. 

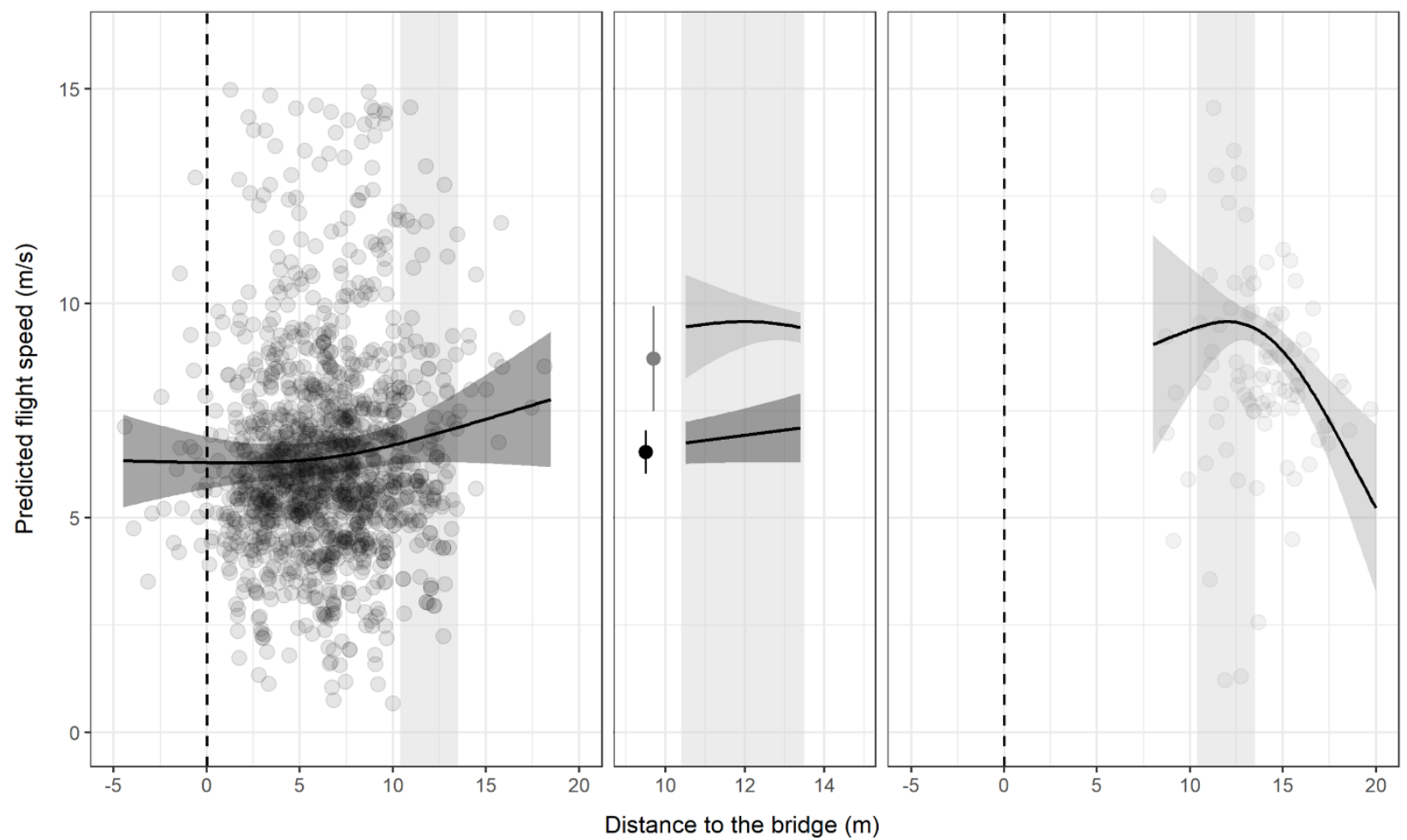

284 Figure 2. Predicted relationships between the flight speed and the bat-bridge distance for unlit (dark grey, left 285 panel) and lit sites (light grey, right panel) and associated 95\% confidence intervals from the linear mixed model presented in Table 2. The light grey rectangles and the focus on it in the middle panel show the overlap of the $95 \%$ confidence interval of bat distances from lit bridges and the $95 \%$ confidence interval of bat distances from unlit bridges, for which direct comparison is the most reliable. Solid dots in the middle panel show predicted average flight speeds in the overlap zone. Vertical dashed lines show the bridge location, and empty circles show raw data used in models. 


\section{Discussion}

293 Results show that compared to unlit bridges, bats approaching illuminated bridges kept a

294

295 greater distance, were less abundant, and increased flight speed instead of slowing down. Although these results have to be taken with cautious given the number of sampled sites (i.e. 6 bridges) due to technical constraints, we think we can be confident in their accuracy thanks to the innovative approach of 3D acoustic localisation which allowed to measure a high number of positions (i.e. 2 187) with high precisions (i.e. $22.1 \pm 24.2 \mathrm{~cm}$ ). In addition, we cannot exclude an effect of particular conditions in samples correlated to lit-unlit characteristics of sites. However, the sampling was designed to control for environmental conditions by selecting sites as similar as possible, and we found a bat activity always lower at unlit sites (i.e. 179, 212, 253 bat passes per site) than at lit sites (i.e. 106, 136, 144). Further studies with a higher sample size to limit potential effects of inherent site characteristics would therefore be necessary to confirm our results.

These results are also consistent with previous studies showing that for this group (i.e. Pipistrellus species), light at night can result in a decrease of bat activity (Azam et al., 2016), can limit the presence of feeding buzzes (Kerbiriou et al., 2020), reduces the crossing probability of gaps in wooded corridors within a city (Hale et al., 2015), and that flight speeds are much higher in presence of light (Polak et al., 2011).

Given the high importance of riverine corridors for bats in urbanized areas with little green spaces (Lintott et al., 2015), our results suggest that bridge lighting reduces bat activity in an important habitat and could potentially constitute a barrier for moving along waterways by preventing individuals from approaching and crossing bridges, and hence affect the functional connectivity for bats in urban landscapes (Laforge et al., 2019; Pauwels et al., 2019).

The considerably lower number of bat passes found near illuminated bridges, and the increase in flight speed in response to light is particularly interesting as Pipistrellus species are 
commonly considered as light-tolerant when studied at a similar spatial scale (Clémentine Azam et al., 2015; Azam et al., 2018; Spoelstra et al., 2017; Zeale et al., 2018). Indeed, as light sources used for street lighting massively attract insects (Wakefield et al., 2016), Pipistrellus species often increase foraging activity around these and reduce their flight speed (Grodzinski et al., 2009). We hypothesise that bats may increase flight speed when their fear for predators outweighs the benefits of foraging at a specific location. The absence of feeding buzzes (i.e. foraging) at lit sites is consistent with this hypothesis: individuals fly faster in highly lit environments reduce foraging behaviour (Grodzinski et al., 2009). This response has been observed in other mammal taxa as well (Farnworth et al., 2019; Hof et al., 2012). We finally show that bats decrease their flight speed while approaching unlit bridges. This is presumably linked to the bridge that forces individuals to slow down to avoid it. Although we accounted for differences in sampling bat-bridge distances between unlit and lit sites by adding the array-bridge distance as a covariate in models, the range of array-bridge distances shared by unlit and lit sites was narrow, which calls for caution in interpreting results about bat-bridge distances for the whole lighting influence area. However, even though we lack data between zero and seven meters from lit bridges (Fig. 2), flight speed response to the distance to bridges and number of bat passes are different enough between lit and unlit sites to be confident about these results.

In our study, we were able to only explore the response of fast-flying species such as Pipistrellus species often described as light-tolerant at the street light scale (Lacoeuilhe et al., 2014), but the response of other bat groups - such as slow-flying light-shy bats - that also rely on aquatic corridors as we tested here will be highly interesting as well. Such negative effects on Pipistrellus species thus raise numerous questions about less tolerant species, especially in more rural landscapes where light-shy bats are regularly more abundant than in urban landscape (Gili et al., 2020). In addition, $P$. pipistrellus and $P$. pygmaeus may respond 
342 differently to light as these species are smaller than $P$. kuhlii/nathusii (Dietz et al., 2009), and

343 hence have different flight characteristics (e.g. Azam et al., 2018; C. Azam et al., 2015; Russo

344 et al., 2018). Further studies are needed to assess species-specific changes in flight patterns

345 due to artificial light.

346 Our results highlight that even for the most common bat species in urban habitat, which is

347 considered as light-tolerant in direct response to light, we found a strong impact of light on

348 the relative abundance near bridges, and on the spatial distribution and flight behaviour. The

349 effects we report here call for keeping bridges dark to preserve the functionality of river

350 corridors and to limit habitat loss for bats. 


\section{Acknowledgments}

353 This work was supported by the Infrastructures de Transports Terrestres, Ecosystèmes et 354 Paysages (ITTECOP-MTES) program, including funding sources from the Agence de 355 l'Environnement et de la Maîtrise de l'Énergie (ADEME), the Fondation pour la Recherche 356 sur la Biodiversité (FRB) and the Club Infrastructures Linéaires et Biodiversité (CIL\&B). We 357 are grateful towards Julie Pauwels and Charlotte Roemer which recently help to improve R 358 script allowing to reconstruct 3D bat trajectories. We also thank Danilo Russo and one 359 anonymous reviewer for their comments which improved our manuscript.

\section{Author's contribution}

K.B., I.L., C.K, R.K.I. and K.S. conceived the ideas and designed the methodology; K.B. and S.C. collected the data, K.B. and Y.B. prepared the data and wrote R scripts; K.B, C.K. and authors gave their final approval for publication.

\section{Data availability}

Data and R scripts used to prepare data are available at the following link https://doi.org/10.5281/zenodo.3929723. 


\section{References}

373

Akasaka, T., Akasaka, M., Nakamura, F., 2012. Scale-independent significance of river and riparian zones on three sympatric Myotis species in an agricultural landscape. Biol. Conserv. 145, 15-23. https://doi.org/10.1016/j.biocon.2011.08.017

Altermatt, F., Ebert, D., 2016. Reduced flight-to-light behaviour of moth populations exposed to long-term urban light pollution. Biol. Lett. 12, 3-6. https://doi.org/10.1098/rsbl.2016.0111

Ancillotto, L., Bosso, L., Salinas-Ramos, V.B., Russo, D., 2019. The importance of ponds for the conservation of bats in urban landscapes. Landsc. Urban Plan. 190, 103607. https://doi.org/10.1016/j.landurbplan.2019.103607

Azam, C., Kerbiriou, C., Vernet, A., Julien, J.-F., Bas, Y., Plichard, L., Maratrat, J., Le Viol, I., 2015. Is part-night lighting an effective measure to limit the impacts of artificial lighting on bats? Glob. Chang. Biol. 21. https://doi.org/10.1111/gcb.13036

Azam, Clémentine, Kerbiriou, C., Vernet, A., Julien, J.F., Bas, Y., Plichard, L., Maratrat, J., Le Viol, I., 2015. Is part-night lighting an effective measure to limit the impacts of artificial lighting on bats? Glob. Chang. Biol. 21, 4333-4341. https://doi.org/10.1111/gcb.13036

Azam, C., Le Viol, I., Bas, Y., Zissis, G., Vernet, A., Julien, J.-F., Kerbiriou, C., 2018. Evidence for distance and illuminance thresholds in the effects of artificial lighting on bat activity. Landsc. Urban Plan. 175, 123-135. https://doi.org/10.1016/j.landurbplan.2018.02.011

Azam, C., Le Viol, I., Julien, J.F., Bas, Y., Kerbiriou, C., 2016. Disentangling the relative effect of light pollution, impervious surfaces and intensive agriculture on bat activity 
with a national-scale monitoring program. Landsc. Ecol. 31, 2471-2483. https://doi.org/10.1007/s10980-016-0417-3

Bas, Y., Bas, D., Julien, J., 2017. Tadarida : A Toolbox for Animal Detection on Acoustic Recordings. J. open Res. Softw. 5, 1-8. https://doi.org/https://doi.org/10.5334/jors.154

Bennie, J., Davies, T.W., Cruse, D., Inger, R., Gaston, K.J., 2018. Artificial light at night causes top-down and bottom-up trophic effects on invertebrate populations. J. Appl. Ecol. 55, 2698-2706. https://doi.org/10.1111/1365-2664.13240

Carrasco-Rueda, F., Loiselle, B.A., 2019. Do riparian forest strips in modified forest landscapes aid in conserving bat diversity? Ecol. Evol. 4192-4209. https://doi.org/10.1002/ece3.5048

Cravens, Z.M., Brown, V.A., Divoll, T.J., Boyles, J.G., Abdullah, E., Idris, A., Saparon, A., 2017. Illuminating prey selection in an insectivorous bat community, exposed to artificial light at night. J. Appl. Ecol. 12, 3218-3221. https://doi.org/10.1111/ijlh.12426

Davies, T.W., Bennie, J., Gaston, K.J., 2012. Street lighting changes the composition of invertebrate communities. Biol. Lett. 8, 764-767. https://doi.org/10.1098/rsbl.2012.0216

De Jong, M., Caro, S.P., Gienapp, P., Spoelstra, K., Visser, M.E., 2017. Early Birds by Light at Night: Effects of Light Color and Intensity on Daily Activity Patterns in Blue Tits. J. Biol. Rhythms 32, 323-333. https://doi.org/10.1177/0748730417719168

Dietz, C., VonHelversen, O., Nill, D., 2009. Bats ofBritain, Europe and Nortwest Africa: London: A\&C Black Publishers.

Downs, N.C., Racey, P.A., 2006. The use by bats of habitat features in mixed farmland in Scotland NICK. Acta chiropterologica 8, 169-185. https://doi.org/10.3161/1733$5329(2006) 8$ 
Eisenbeis, G., 2006. Artificial night lighting and insects: attraction of insects to streetlamps in a rural setting in Germany, in: Ecological Consequences of Artificial Night Lighting (Eds C Rich, T Longcore), Washington, DC: Island Press. pp. 281-304. https://doi.org/10.1017/CBO9780511609763.016

Farnworth, B., Meitern, R., Innes, J., Waas, J.R., 2019. Increasing predation risk with light reduces speed, exploration and visit duration of invasive ship rats (Rattus rattus). Sci. Rep. 9, 3739. https://doi.org/10.1038/s41598-019-39711-3

Fox, R., 2013. The decline of moths in Great Britain: A review of possible causes. Insect Conserv. Divers. 6, 5-19. https://doi.org/10.1111/j.1752-4598.2012.00186.x

Frank, K.D., 1988. Impact of Outdoor Lighting on Moths. J. Lepid. Soc. 2, 63-93. https://doi.org/10.1017/s0252921100003687

Gaston, K.J., Davies, T.W., Nedelec, S.L., Holt, L.A., 2017. Impacts of Artificial Light at Night on Biological Timings. Annu. Rev. Ecol. Evol. Syst. 48, 49-68. https://doi.org/10.1146/annurev-ecolsys-110316-022745

Gili, F., Newson, S.E., Gillings, S., Chamberlain, D.E., Border, J.A., 2020. Bats in urbanising landscapes: habitat selection and recommendations for a sustainable future. Biol. Conserv. 241, 108343. https://doi.org/10.1016/j.biocon.2019.108343

Götze, S., Denzinger, A., Schnitzler, H., 2020. High frequency social calls indicate food source defense in foraging Common pipistrelle bats. Sci. Rep. 10, 5764. https://doi.org/10.1038/s41598-020-62743-z

Grindal, S.D., Morissette, J.L., Brigham, R.M., 1999. Concentration of bat activity in riparian habitats over an elevational gradient. Can. J. Zool. 77, 972-977. https://doi.org/10.1139/z99-062 
Grodzinski, U., Spiegel, O., Korine, C., Holderied, M.W., 2009. Context-dependent flight speed: Evidence for energetically optimal flight speed in the bat Pipistrellus kuhlii? J. Anim. Ecol. 78, 540-548. https://doi.org/10.1111/j.1365-2656.2009.01526.x

Guetté, A., Godet, L., Juigner, M., Robin, M., 2018. Worldwide increase in Artificial Light At Night around protected areas and within biodiversity hotspots. Biol. Conserv. 223, 97103. https://doi.org/S0006320717319043

Hale, J.D., Fairbrass, A.J., Matthews, T.J., Davies, G., Sadler, J.P., 2015. The ecological impact of city lighting scenarios: Exploring gap crossing thresholds for urban bats. Glob. Chang. Biol. 21, 2467-2478. https://doi.org/10.1111/gcb.12884

Hof, A.R., Snellenberg, J., Bright, P.W., 2012. Food or fear? Predation risk mediates edge refuging in an insectivorous mammal. Anim. Behav. 83, 1099-1106. https://doi.org/10.1016/j.anbehav.2012.01.042

Hölker, F., Wolter, C., Perkin, E.K., Tockner, K., 2010. Light pollution as a biodiversity threat. Trends Ecol. Evol. 25, 681-682. https://doi.org/10.1016/j.tree.2010.09.007

Ing, R.K., Colombo, R., Gembu, G.-C., Bas, Y., Julien, J.-F., Gager, Y., Hassanin, A., 2016. Echolocation Calls and Flight Behaviour of the Elusive Pied Butterfly Bat ( Glauconycteris superba), and New Data on Its Morphology and Ecology. Acta Chiropterologica 18, 477-488. https://doi.org/10.3161/15081109ACC2016.18.2.014

Jechow, A., Hölker, F., 2019. How dark is a river? Artificial light at night in aquatic systems and the need for comprehensive night-time light measurements. Wiley Interdiscip. Rev. Water 1-19. https://doi.org/10.1002/wat2.1388

Jones, G., Rydell, J., 1994. Foraging strategy and predation risk as factors influencing emergence time in echolocating bats. Philos. Trans. R. Soc. B Biol. Sci. 346, 445-455. 
465

Kerbiriou, C., Barré, K., Mariton, L., Pauwels, J., Zissis, G., Robert, A., Le Viol, I., 2020. Switching LPS to LED Streetlight May Dramatically Reduce Activity and Foraging of Bats. Diversity 12. https://doi.org/10.3390/d12040165

Kerbiriou, C., Bas, Y., Le Viol, I., Lorrillière, R., Mougnot, J., Julien, J.-F., 2019. Bat Pass Duration Measurement: An Indirect Measure of Distance of Detection. Diversity 11, 47. https://doi.org/10.3390/d11030047

Knop, E., Zoller, L., Ryser, R., Gerpe, C., Hörler, M., Fontaine, C., 2017. Artificial light at night as a new threat to pollination. Nature 548, 206-209. https://doi.org/10.1038/nature23288

Koblitz, J.C., 2018. Arrayvolution: using microphone arrays to study bats in the field. Can. J. Zool. 96, 933-938. https://doi.org/10.1139/cjz-2017-0187

Koen, E.L., Minnaar, C., Roever, C.L., Boyles, J.G., 2018. Emerging threat of the 21st century lightscape to global biodiversity. Glob. Chang. Biol. 24, 2315-2324. https://doi.org/10.1111/gcb.14146

Lacoeuilhe, A., Machon, N., Julien, J.F., Kerbiriou, C., 2016. Effects of hedgerows on bats and bush crickets at different spatial scales. Acta Oecologica 71, 61-72. https://doi.org/10.1016/j.actao.2016.01.009

Lacoeuilhe, A., Machon, N., Julien, J.F., Le Bocq, A., Kerbiriou, C., 2014. The influence of low intensities of light pollution on bat communities in a semi-natural context. PLoS One 9. https://doi.org/10.1371/journal.pone.0103042

Laforge, A., Pauwels, J., Faure, B., Bas, Y., Kerbiriou, C., Fonderflick, J., Besnard, A., 2019. Reducing light pollution improves connectivity for bats in urban landscapes. Landsc. 
Ecol. 34, 793-809. https://doi.org/10.1007/s10980-019-00803-0

488

489

490

491

492

493

494

495

496

497

498

499

500

501

502

503

504

505

506

507

508

509

Lintott, P.R., Bunnefeld, N., Park, K.J., 2015. Opportunities for improving the foraging potential of urban waterways for bats. Biol. Conserv. 191, 224-233. https://doi.org/10.1016/j.biocon.2015.06.036

Lloyd, A., Law, B., Goldingay, R., 2006. Bat activity on riparian zones and upper slopes in Australian timber production forests and the effectiveness of riparian buffers. Biol. Conserv. 129, 207-220. https://doi.org/10.1016/j.biocon.2005.10.035

Lookingbill, T.R., Elmore, A.J., Engelhardt, K. a. M.M., Churchill, J.B., Edward Gates, J., Johnson, J.B., 2010. Influence of wetland networks on bat activity in mixed-use landscapes. Biol. Conserv. 143, 974-983. https://doi.org/10.1016/j.biocon.2010.01.011

Minnaar, C., Boyles, J.G., Minnaar, I.A., Sole, C.L., Mckechnie, A.E., 2015. Stacking the odds: Light pollution may shift the balance in an ancient predator-prey arms race. J. Appl. Ecol. 52, 522-531. https://doi.org/10.1111/1365-2664.12381

Pauwels, J., Viol, I. Le, Azam, C., Valet, N., Julien, J. -f., Bas, Y., Lemarchand, C., Miguel, A.S. De, Kerbiriou, C., 2019. Accounting for artificial light impact on bat activity for a biodiversity-friendly urban planning. Landsc. Urban Plan. 183, 12-25. https://doi.org/S0169204618311939

Penone, C., Kerbiriou, C., Julien, J.-F., Julliard, R., Machon, N., Le Viol, I., 2013. Urbanisation effect on Orthoptera: which scale matters? Insect Conserv. Divers. 6, 319327. https://doi.org/10.1111/j.1752-4598.2012.00217.x

Perkin, E.K., Hölker, F., Tockner, K., 2014. The effects of artificial lighting on adult aquatic and terrestrial insects. Freshw. Biol. 59, 368-377. https://doi.org/10.1111/fwb.12270

Pinaud, D., Claireau, F., Leuchtmann, M., Kerbiriou, C., 2018. Modelling landscape 
connectivity for greater horseshoe bat using an empirical quantification of resistance. J. Appl. Ecol. 55, 2600-2611. https://doi.org/10.1111/1365-2664.13228

Polak, T., Korine, C., Yair, S., Holderied, M.W., 2011. Differential effects of artificial lighting on flight and foraging behaviour of two sympatric bat species in a desert. J. Zool. 285, 21-27. https://doi.org/10.1111/j.1469-7998.2011.00808.x

R Core Team, 2018. R: A Language and Environment for Statistical Computing [WWW Document]. R Found. Stat. Comput. Vienna, Austria. URL https://www.r-project.org/

Russo, D., Ancillotto, L., Cistrone, L., Libralato, N., Domer, A., Cohen, S., Korine, C., 2018. Effects of artificial illumination on drinking bats: a field test in forest and desert habitats. Anim. Conserv. 1-10. https://doi.org/10.1111/acv.12443

Russo, D., Cistrone, L., Libralato, N., Korine, C., Jones, G., Ancillotto, L., 2017. Adverse effects of artificial illumination on bat drinking activity. Anim. Conserv. 20, 492-501. https://doi.org/10.1111/acv.12340

Russo, D., Cosentino, F., Festa, F., De Benedetta, F., Pejic, B., Cerretti, P., Ancillotto, L., 2019. Artificial illumination near rivers may alter bat-insect trophic interactions. Environ. Pollut. 252, 1671-1677. https://doi.org/10.1016/j.envpol.2019.06.105

Rydell, J., 1992. Exploitation of Insects around Streetlamps by Bats in Sweden. Funct. Ecol. 6, 744. https://doi.org/10.2307/2389972

Salinas-Ramos, V.B., Ancillotto, L., Bosso, L., Sánchez-Cordero, V., Russo, D., 2020. Interspecific competition in bats: state of knowledge and research challenges. Mamm. Rev. 50, 68-81. https://doi.org/10.1111/mam.12180

Sirami, C., Jacobs, D.S., Cumming, G.S., 2013. Artificial wetlands and surrounding habitats provide important foraging habitat for bats in agricultural landscapes in the Western 

Cape, South Africa. Biol. Conserv. 164, 30-38. https://doi.org/10.1016/j.biocon.2013.04.017

Smith, P.G., Racey, P.A., 2008. Natterer's bats prefer foraging in broad-leaved woodlands and river corridors. J. Zool. 275, 314-322. https://doi.org/10.1111/j.14697998.2008.00445.x

Spoelstra, K., Ramakers, J.J.C., van Dis, N.E., Visser, M.E., 2018. No effect of artificial light of different colors on commuting Daubenton's bats (Myotis daubentonii) in a choice experiment. J. Exp. Zool. Part A Ecol. Integr. Physiol. 329, 506-510. https://doi.org/10.1002/jez.2178

Spoelstra, K., van Grunsven, R.H.A., Ramakers, J.J.C., Ferguson, K.B., Raap, T., Donners, M., Veenendaal, E.M., Visser, M.E., 2017. Response of bats to light with different spectra: light-shy and agile bat presence is affected by white and green, but not red light. Proc. R. Soc. B Biol. Sci. 284, 20170075. https://doi.org/10.1098/rspb.2017.0075

Todd, V.L.G., Williamson, L.D., 2019. Habitat usage of Daubenton's bat (Myotis daubentonii), common pipistrelle (Pipistrellus pipistrellus), and soprano pipistrelle (Pipistrellus pygmaeus) in a North Wales upland river catchment. Ecol. Evol. 48534863. https://doi.org/10.1002/ece3.5085

Wakefield, A., Broyles, M., Stone, E.L., Jones, G., Harris, S., 2016. Experimentally comparing the attractiveness of domestic lights to insects: Do LEDs attract fewer insects than conventional light types? Ecol. Evol. 6, 8028-8036. https://doi.org/10.1002/ece3.2527

Zeale, M.R.K., Stone, E.L., Zeale, E., Browne, W.J., Harris, S., Jones, G., 2018. Experimentally manipulating light spectra reveals the importance of dark corridors for commuting bats. Glob. Chang. Biol. 24, 5909-5918. https://doi.org/10.1111/gcb.14462 
